\title{
Development of an algorithm to identify mass production candidate molecules to develop children's oral medicines: a North American perspective
}

\author{
Varsha Bhatt-Mehta ${ }^{1,2^{*}}$ (D, Robert B. MacArthur ${ }^{3}$, Raimar Löbenberg ${ }^{4,5}$, Jeffrey J. Cies ${ }^{2,6,7}$, Ibolja Cernak ${ }^{2,8}$
} and Richard H. Parrish $\|^{2,7}$

\begin{abstract}
The gap in the commercially-available pediatric drug products and formulations suitable for children, especially those below the age of 6 years, is long recognized. A group of clinicians and scientists with a common interest in pediatric drug development and medicines-use systems developed a practical framework for identifying a list of active pharmaceutical ingredients (APIs) with the greatest market potential for development to use in pediatric patients. Reliable and reproducible evidence-based drug formulations designed for use in pediatric patients are needed vitally, otherwise safe and consistent clinical practices and outcomes assessments will continue to be difficult to ascertain. Identification of a prioritized list of candidate APIs for oral formulation using the described algorithm provides a broader integrated clinical, scientific, regulatory, and market basis to allow for more reliable dosage forms and safer, effective medicines use in children of all ages. Group members derived a list of candidate API molecules by factoring in a number of pharmacotherapeutic, scientific, manufacturing, and regulatory variables into the selection algorithm that were absent in other rubrics. These additions will assist in identifying and categorizing prime API candidates suitable for oral formulation development. Moreover, the developed algorithm aids in prioritizing useful APIs with finished oral liquid dosage forms available either adapted from other countries or the aim to register them in North America and beyond.
\end{abstract}

\section{Background}

Childhood illnesses often require the use of medications under the premise of "off-label" use. In February 2014, the American Academy of Pediatrics (AAP) released a policy statement from its Committee on Drugs regarding the off-label use of drugs (medications) in children (Committee on Drugs 2014). For the purpose of the statement the Committee defined "off-label" use as "that use which is not included in the package insert (Food and Drug Administration (FDA)-approved labeling) for that drug and is "neither experimentation nor research" (Committee on Drugs 2014). Such off-label use of drugs

\footnotetext{
* Correspondence: rxvarsha@gmail.com

'Department of Clinical, Social and Administrative Sciences, College of Pharmacy and Department of Pediatrics, Medical School, University of Michigan, Edmonton, AB, Canada

${ }^{2}$ Med4Kids Research Collaborative, Ltd, Edmonton, AB, Canada

Full list of author information is available at the end of the article
}

in children does not require any oversight by any institutional (Investigational Review Board) or federal regulatory agency. Use of drugs without appropriate research in children can put this population at significant risk for adverse events. Off-label use combined with use of medication management systems designed for adults and adapted for use in children can compound the risk of adverse events due to increased potential for medication errors. We have addressed the issue of medication management systems in a Special Issue of Pharmacy Paediatrics, published recently in the online journal, Pharmacy, at mdpi.com (Parrish \& Cernak 2015). Here, we make an attempt to identify other issues related to off-label use of drugs, and present a systematic approach to selection of API candidate molecules amenable to a novel formulation methodology suitable for children. 


\section{Why is off-label use of drugs in children still a problem?}

The issue of off-label use of drugs in neonates, infants and children has prevailed for many decades. Federal legislation to address this issue was first proposed in 1998 and reauthorized in 2012. Since that time, various government agencies including FDA and the National Institute of Child Health and Human Development (NICHD) have worked together to develop pediatricinclusive product labeling for existing and new drug molecules coming to the market, if the drug has been or could be used in children. The European Medicines Agency (EMA) also adopted a similar legislation in 2007.

According to a recent study published in JAMAPediatrics, the US legislation has produced 406 pediatric labeling changes; out of those, only 24 labels include data on neonatal drug dosing (Laughon et al. 2014). The EMA regulation found the number of pediatric investigation plans increased for new molecular entities, but it also identified neonates as the least studied population after the new legislation was introduced (Better Medicines for Children: From Concept to Reality 2013). Identified factors for lack of appropriate drug dosing data in children go beyond the efforts of the FDA and NICHD, which formed partnership almost two decades ago to address this issue and formed collaborations with academia and a number of other entities to enhance this knowledge. Some have also called into question the ethics of non-beneficial pediatric research, that is, what is good clinical practice on permissible risk in incompetent (pediatric) patients? (Piasecki et al. 2015) Current dosing regimens of most drugs used in neonates, infants and children are derived from extrapolation of adult data rather than from systematic pharmacokinetic (PK)/pharmacodynamics (PD) study of drugs in these populations. A major barrier to generation of appropriate dosing regimens based on sound PK/PD data is lack of uniform drug formulation. Many dosage forms of drugs used in these populations today in institutions in US and in the world are extemporaneously compounded and lack validated product uniformity. Often, clinical trials protocols include products prepared using non-standard compounding methods at the site of the investigation. These formulation factors can result in significant variability in drug disposition studies since it is often unclear whether the variation originates from the patient or the product. Thus, translational research in pediatrics is not only necessary for new drug moieties, but also for approved pharmaceuticals used frequently without regard to dosage forms and formulation properties, both of which could significantly affect their bioavailability, plasma concentrations and therapeutic effect.

In practice, children less than 12 years of age are generally not able or prefer not to swallow tablets or capsules, thus frequently requiring a liquid dosage form, or a soluble or chewable preparation. Unfortunately, there is a distinct lack of such formulations on the market which leads to extemporaneous compounding as the only practicable resolution (Nahata \& Allen 2008). There are many reasons for this market deficiency including formulation difficulties and identification of suitable existing and new APIs amenable to liquid/soluble formulations. The diversity of the pediatric population (age range, physical size and swallowing capabilities) which varies significantly from birth to 12 years of age, along with the variability in dosing based on size, age, weight etc. produces many challenges in pediatric formulation development mostly associated with the difficulty in defining design of the intended dosage form that is most appropriate for the target patient population.

Traditionally, to enhance the solubility of poorly soluble compounds by conventional formulation approaches in most cases, drug formulation is developed with an aim to create a supersaturated solution when it comes into contact with an aqueous environment. This often requires use of solubilizing agents and precipitation inhibitors. Some of the other popular formulations approaches for achieving this solubilization are the lipid-based formulations called self-emulsifying and self-micro emulsifying drug delivery systems. These systems enhance solubility and hence oral bioavailability of lipophilic drugs, presenting the drug in solubilized form in vivo. This phenomenon avoids dissolution, which can be the rate limiting step in drug absorption for sparingly soluble drugs. It also avoids addition of solubilizing agents or precipitation inhibitors reducing excipient exposures. Some other technologies used to improve drug solubility and bioavailability includes the production of high energy or rapid dissolving solid state formulations using drug particle engineering. Examples of such formulations include solid dispersions, nanoparticles, and co-ground mixtures (Charkoftaki et al. 2012).

In recent years, there has been an increased effort to develop solid pediatric formulations that deliver the appropriate dose in a "user friendly" way and to find alternative drug delivery vehicles, such as mini-tablets as well as new taste masking techniques in order to improve drug acceptability in children. Solid state formulations such as mini tabs have a limitation in that they still lack the dosing accuracy needed for dosing the very young patient less than 1 year of age where liquid formulations are preferred for ease of administration as well as accuracy of dosing since dosing in this group of patients is generally weight based and often results in fractional dosing. This leads to continual need for extemporaneous compounding for this patient population.

In the following sections, we present a rubric that incorporates clinical and market-oriented variables in relation to existing APIs commonly used in pediatric practice that lack mass-produced formulations suitable for younger patients less than 6 years of age, despite 
development of several new technologies in recent years for pediatric population friendly formulations described above. The purpose of this rubric is to easily identify such molecules and explore the possibility of production of physically and chemically stab le formulations with a long shelf life that can be made available for easy use as well as help alleviate or minimize extemporaneous compounding. We overlay an array of scientific factors that support the selection of these APIs for mass-production, including Biopharmaceutical Classification System (BCS) and propose hot-melt extrusion (HME) process, a technology that has received significant attention in recent years, as a potentially flexible liquid formulation production technique for low solubility APIs suitable for a wide range of pediatric patients including premature neonates.

\section{Development of the algorithm for a tiered selection model for candidate APIs}

Between September and December 2013, a North-American group of pharmacists, pediatricians, and pharmaceutical scientists formed Meds4Kids Research Collaborative, LTD (M4KRC). This group of clinicians and scientists with a common interest in pediatric drug development and medicines-use systems developed a framework for developing drugs in dosage forms suitable for use in pediatric patients (Fig. 1). The group met in a series of six conference calls to determine a list of candidate
API molecules that possessed the greatest clinical, scientific, and market potential for mass production. The proposed criteria for determining potential candidate API molecules were prioritized primarily based on Best Pharmaceuticals for Children Act (BPCA), which lists broad-based clinical developmental needs within pediatrics. Below is the first phase rubric that the group selected for the API molecules:

1. Listed on BPCA priority document (clinical need broad base);

2. Available in an injection (compound is stable in solution for at least 18-24 months);

3. Not a federally controlled substance in Canada or the US (minimal paperwork for chain of custody);

4. Potential applicability for oral adult market (for patients that cannot swallow tablets or capsules);

5. Established indication for any age group in the official labeling of the compound (immediate marketability through accelerated mechanisms) and

6. Off-patent in both Canada and the US, and available in a pharmaceutical grade powder from a reputable supplier.

The group reviewed the BPCA list and compared it to the list of 50 compounded non-sterile products (CNPs) prepared extemporaneously at St. Christopher's Hospital for Children, all of which had scientific evidence for

Meds4Kids Research Collaborative, LTD.

Framework for Pediatric Product Development

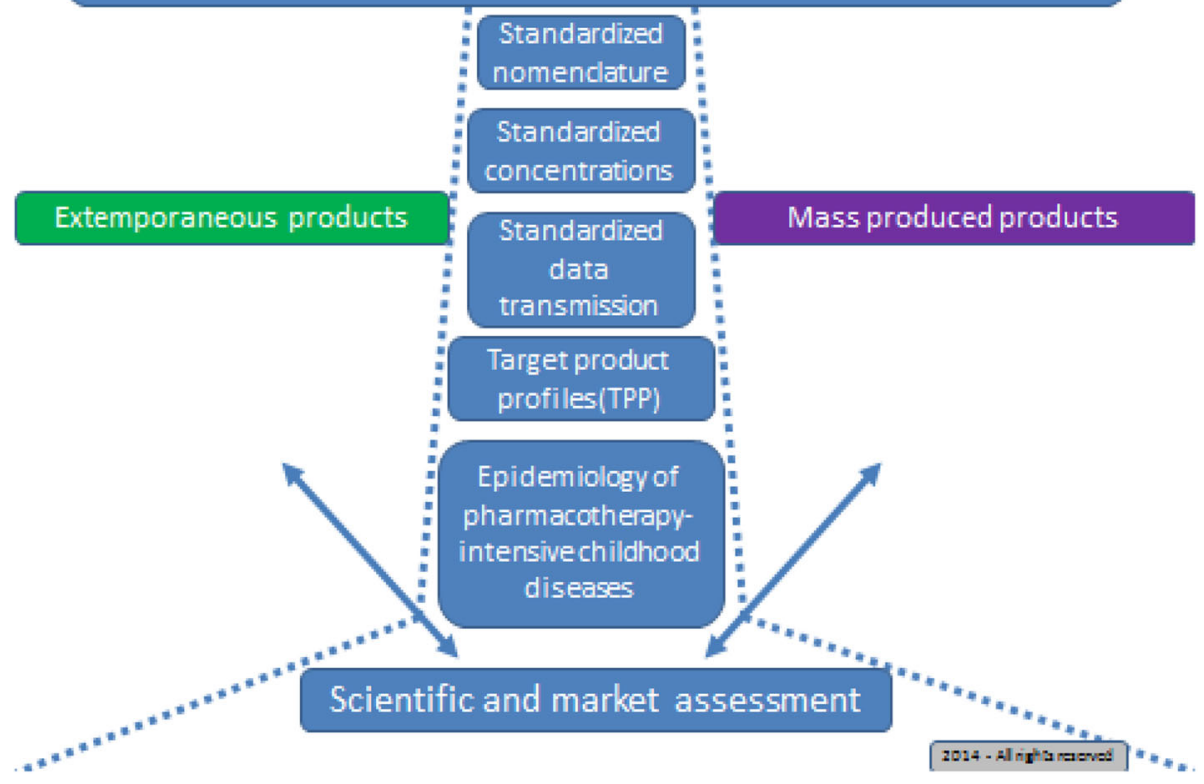

Fig. 1 M4KRC framework for collaborative pediatric drug development 
stability in a standardized concentration (Compounded non-sterile product list 2013 St. Christopher's Hospital for Children, unpublished). The clinicians (VBM, RHP, and JJC) adjudicated the list using a scoring system that assigned a score for each API molecule's potential from a pharmacotherapy perspective. In the third meeting, a seventh factor was incorporated into the algorithm; the availability of a mass-produced oral liquid dosage form in the United Kingdom. Then, in the last two meetings, the scientists (RBM and RL) integrated the clinician-derived list with the biopharmaceutical properties that complemented and validated the clinical rankings for the identified APIs.

The original list was then segmented into four tiers:

- The first tier included API molecules that met at least five of the six criteria;

- The second tier fulfilled four criteria;

- The third tier included API molecules not listed by name in the BPCA list but met all other criteria except availability in the United Kingdom; and

- The fourth tier included those available in the UK that could be imported readily for pharmacokinetic (PK), pharmacodynamics (PD), and/or pharmacogenomics (PG) studies in children.

Several API molecules were removed from the list because of new market entry (enalapril), availability of one oral liquid strength (levetiracetam), known physicochemical problems (acetylsalicylic acid), or low use potential in children (pravastatin). The final, fourth tier API molecules, identified based on criteria of potential viability as candidates ready for PK/PD/PG studies, are listed in Table 1.

\section{Effective drug delivery and viable mass manufacturing - applying BCS and HME to candidate APIs}

The next step for the group was to apply scientific principles of drug delivery and formulation techniques to the clinically-derived list that would enhance the likelihood of the commercial availability of a mass-produced product. Effective delivery and viable manufacturing are essential to improve the clinical and commercial value of a pharmaceutical product. A reliable formulation will not only ensure optimal clinical outcomes, but also assure reproducibility in manufacturing, increased stability and longer shelf life making the product economically viable. The gap in the commercially available pediatric drug products and dosage forms, which is long recognized, is currently bridged daily primarily by the efforts of compounding pharmacists, especially in the hospital setting. APIs are routinely compounded extemporaneously from adult solid oral dosage forms into liquid forms to provide medications that otherwise are not available to vulnerable pediatric populations, such as children with cardiovascular disease, cancer, cystic fibrosis, organ transplants, and other life threatening and rare diseases.

It has been noted that these compounding practices, despite best efforts and intentions, do not incorporate the necessary manufacturing controls to assure reproducible product potency, stability, and purity. Formal efforts to assist pharmacists and other practitioners to compound the best products possible include methods and guidelines found in the United States Pharmacopeia, FDA regulations and guidance documents, professional working groups, and elsewhere (Compounding Compendium). Working groups focusing on the topic date back to at least 1977, when the American Society of Hospital Pharmacists Special Interest Group on Pediatric Pharmacy Practice started working on the issue. This group continues to meet to the current day (Jew et al. 2010).

When compared to Good Manufacturing Practices (GMPs), the manufacturing standards required by FDA for commercial products, there are multiple recognized deficiencies inherent in extemporaneous formulationcompounding suitable for pediatric patients, which include the following:

- Lack of specifications required for component development by compounding pharmacies.

- No onsite testing of active ingredients and excipients for purity, potency, content and stability.

Table 1 M4KRC fourth tier candidate API molecules

\begin{tabular}{llllllll}
\hline Generic name & BCPA listed? & Injection? & Non-scheduled? & Oral adult market? & Established adult indication? & Off patent? & Dose form in UK? \\
\hline Baclofen & 1 & 1 & 1 & 1 & 1 & 1 & Yes $^{\text {a }}$ \\
Warfarin & 1 & 1 & 1 & 1 & 1 & 1 & Yes $^{\text {b }}$ \\
Sildenafil & 1 & 1 & 1 & 1 & 1 & 1 & Yes $^{c}$ \\
L-thyroxine & 1 & 1-lyo & 1 & 1 & 1 & 1 & Yes $^{\text {d }}$ \\
\hline
\end{tabular}

${ }^{2}$ Available as $5 \mathrm{mg} / \mathrm{mL}$ oral solution at http://medicines.org.uk/emc/medicine/14939/SPC/Lyflex+5mg+5ml+Oral+Solution/

${ }^{\mathrm{b}}$ Available as $1 \mathrm{mg} / \mathrm{mL}$ oral suspension at http://medicines.org.uk/emc/medicine/23933/SPC/Warfarin+Sodium+1 mg+1 ml+Oral+Suspension/

CAvailable as $10 \mathrm{mg} / \mathrm{mL}$ suspension powder at http://medicines.org.uk/emc/medicine/27153/SPC/Revatio+10+mg+ml+powder+for+oral+suspension/

${ }^{\mathrm{d}}$ Available as $5 \mathrm{microgram} / \mathrm{mL}$ and $20 \mathrm{microgram} / \mathrm{mL}$ at http://medicines.org.uk/emc/medicine/26562/SPC/Eltroxin+25micrograms+per+5ml+Oral+Solution/ 
- No onsite specifications or testing of preparation containers and closures.

- Site-to-site variations in compounding procedures, equipment, and the degree of preparation handling/ manipulation.

- Lack of environmental control, which might lead to unintentional contamination and generation of degradation products due to inconsistent exposure to light, temperature and processing controls.

- Lack of testing of finished preparations for purity, potency, content or stability.

- Stability data for establishing expiry dates of compounded products are derived from published data, where preparation methods likely vary from local methods, or are simply default expiry periods defined by regional pharmacy regulations and "best practices" or applicable USP Chapters 795, 797 and 1191.

- Published preparation methods provide only a portion of the information needed to consistently prepare a stable potent final compounded preparations.

- Limited options available to mask bad-tasting active ingredients.

- The dose administration technologies used such as droppers, syringes, scoops, spoons, etc., vary between sites and between prescription fills.

- Weak regulatory oversight.

Unfortunately, there are a number of barriers to the development of pediatric drug formulations under GMPs, not the least of which are economic in nature (Vanchieri et al. 2008). The first barrier concerns the market size. The elderly population (65 years of age and older) spends, on average, about 10 times more than the pediatric population ( $0-17$ years of age) on medications. With regard to production, development of a unique pediatric formulation can take up to two years or more, with a cost ranging from $\$ 8$ million to $\$ 15$ million (Milne 2011). The second barrier relates to the need for incorporating taste-masking methods suitable for children; and the third is due to the need to develop dosage forms such as liquids, suspensions, small tablets, films and chewable tablets that can be easily administered to children.

The Biopharmaceutical Drug Classification System (BCS) was introduced by Amidon et al. in 1995 (Amidon et al. 1995). Today, this classification system is accepted by most regulatory agencies like the US FDA, Health Canada and European Medicines Agency (EMA). APIs are classified into one of four quadrants according to their potential bioavailability (Löbenberg \& Amidon 2000). Solubility and permeability are the two parameters used for the classification. Only if a drug can dissolve in the gastrointestinal tract can it be absorbed, and only if it is absorbed it can have a systemic effect. BCS class I drugs have high solubility and high permeability; class II are poorly soluble but highly permeable; class III are highly soluble but poorly permeable and class IV are poorly soluble and poorly permeable. $\mathrm{Wu}$ and Benet linked metabolism to the BCS classification, and showed that class I and II drugs can be highly metabolized and be subject to transporters, while class III and IV drugs are poorly metabolized or transported (Wu \& Benet 2005). If two pharmaceutically equivalent finished drug products with BCS class $1 \& 3$ have similar dissolution behavior at $\mathrm{pH}$ 1.2, 4.5 and 6.8, then they can be considered therapeutically equivalent and bioequivalence has been demonstrated through in vitro methods (Löbenberg et al. 2012) as outlined in the WHO, EMA and Health Canada Biowaiver guidelines (WHO Expert Committee on Specifications for Pharmaceutical Preparations 2006; EMA 2010; Health Canada 2014). FDA currently only grants biowaivers for BCS class 1 APIs (U.S. Department of Health and Human Services Food and Drug Administration Center for Drug Evaluation and Research (CDER) 2000) but might update its guidance in the future to include BCS class three drugs (U.S. Department of Health and Human Services Food and Drug Administration Center for Drug Evaluation and Research (CDER) 2025).

This approach can be used in the development of pediatric dosage forms if an identical strength already exists. The knowledge of the BCS class helps pharmaceutical companies in drug development. For example, a class I drug might need much less formulation work compared to a class II drug where solubility must be improved (Almukainzi et al. 2014). The BCS classes of APIs with the highest potential for pediatric formulation development are listed in Table 2, and could be applied to all WHO-listed essential medicines for children (Takagi et al. 2006; Ramirez et al. 2010; Fiftieth Report of the WHO Expert Committee on Specifications for Pharmaceutical Preparations 2016; Dahan et al. 2013).

One of the manufacturing methods that can address many of the solubility problems of BCS class 2 and 4 drugs is the hot-melt extrusion (HME) technology (Maniruzzaman et al. 2012). HME disperses the active ingredient(s) as a matrix at the molecular level, thus forming solid solutions without the use of excessive heat or solvents while preserving drug potency. The HME approach has been successful in improving the delivery and human absorption of poorly water-soluble compounds. Extruded solid solutions (i.e. the end product of HME) offer greater thermodynamic stability compared to products prepared by alternative processes such as spray drying, solvent evaporation and other hot melt methods.

Concerning economics, HME can be used to produce small (on a GMP scale) lots of a formulated product. The final production sizes of these small lot sizes, 
Table 2 BCS class and potential candidate molecules for pediatric drug development

\begin{tabular}{lll}
\hline Generic name & BCS Class & Reference \\
\hline Metoprolol & I & TRSL \\
Clopidogrel & $\|$ & TRSL \\
Lisinopril & $\|$ & TRSL \\
Amlodipine & Uncl. & TRSL \\
Ursodiol & Uncl. & n.d. \\
Bosentan & Uncl. & n.d. \\
Pantoprazole & IV & n.d. \\
Acetazolamide & $\|$ & TRSL \\
Spironoloactone & I & TRSL \\
Valaciclovir & III & TRSL \\
Captopril & $\|$ & TRSL \\
Nifedipine & Uncl. & TRSL \\
Baclofen & $\|$ & n.d. \\
Warfarin & I & TRSL \\
Sildenafil & I & TRSL \\
L-thyroxine & & TRSL \\
\hline
\end{tabular}

Uncl. unclassified, n.d. no data

aProvisional BCS Classification. http://www.tsrlinc.net/results.cfm

denoted by contract manufacturers as research and development batches or Clinical Trial Manufacturing (CTM) batches, are within the range of 10,000 to 50,000 units. The flexibility to produce small batches using HME process may provide a sufficient commercial market for a given pediatric population for a year or more. Compared to commercial tableting or capsule manufacturing approaches, which incorporate processes such as milling, mixing, spray drying, wet granulation, precompression, compression, tableting/encapsulation,

HME is a much more economical process with reduced production time, fewer processing steps, and is suitable for continuous operation (Abdel-Rahman et al. 2012; Batchelor et al. 2014).

With regards to formulation attributes and taste masking, HME can produce final drug products with sustained, modified, and targeted release properties, and can also coat poor tasting products. So, the finished product can then be milled in a single step to form powders suitable for incorporation into child-friendly dosage forms such as mini-tablets, orally disintegrating tabs, and liquid suspensions. The output of the extrusion process, known as an extrudate, can be optimized to protect the API against changing $\mathrm{pH}$ conditions, light, heat, and moisture levels, thus confer good stability properties to the final formulation. While characterization of the pediatric gut awaits a more complete description, HME provides a useful tool for poorly soluble, highly permeable APIs (Batchelor \& European Paediatric Formulation
Initiative (EUPFI) 2014; Tannergren et al. 2009; Flynn et al. 2014; Crowley et al. 2007).

An example of an API suitable for HME process is metoprolol succinate. Metoprolol is one of the most commonly used beta-blocking agents used in children from infancy through adolescence and into adulthood to treat a variety of cardiovascular conditions as an antihypertensive and heart rate modulator (Repka et al. 2007). Metoprolol succinate is a freely soluble compound according to the Martindale (Sweetman SC). Metoprolol is often used as borderline drug to differentiate between high and low permeability drugs (Löbenberg \& Amidon 2000). The required average pediatric dose ranges from 5 to $50 \mathrm{mg} /$ day. Hence, a minimum concentration of about $2.5 \mathrm{mg} / \mathrm{mL}$, with a maximum concentration of $10 \mathrm{mg} / \mathrm{mL}$ is desired.

Metoprolol is an excellent example of an HME candidate. HME process can increase the dissolution rate of the drug for deriving clinically acceptable concentrations with ease of reconstitution for a given strength. The process will also deliver good content uniformity of the drug and minimize risk for segregation. Overall, the manufacturing process is very simple, and involves only blending and processing using tight process controls. The HME process allows for in-process monitoring of the product quality using process analytical tools (e.g. Near Infra-Red (NIR) Spectroscopy). Moreover, there is no need for scaling up and down for different batch sizes. As with many commercial pediatric formulations currently in use (especially for existing molecules) as well as extemporaneously compounded formulations that still await PK/PD data, the PK/ PD of formulations produced using HME technology would also need to be studied.

In summary, the M4KRC-derived list of candidate API molecules has been derived from selection matrix that factored in a number of pharmacotherapeutic, biopharmaceutical, scientific, manufacturing, and regulatory variables absent in other rubrics. These additions guided the group to identify the prime API candidates suitable for children in mass produced dosage forms. Further, the market-focused algorithm helped to prioritize useful APIs, and to facilitate clinical studies with finished oral liquid dosage forms available from other countries with direct importation potential to North America. BCS lass II molecules are best suited for formulation using HME technologies. However, as seen with metoprolol other factors might also need to be considered. Incorporating BCS classification into the final selection of candidate APIs, the following molecules are suggested for formulation and development: metoprolol, clopidogrel, spironolactone, and nifedipine. The assessment of these other variables, in addition to clinical and market parameters, is very important to increase the likelihood that a pharmaceutical manufacturer would successfully mass-produce 
and market these oral liquid dosage forms for children (Public Assessment Report for paediatric studies submitted in accordance with Article 45 of Regulation (EC) No1901/ 2006 \& as amended. Metoprolol succinate 2013; Allen \& Erickson 1996).

\section{Conclusion}

Successful public private partnerships have moved the science of pediatric clinical pharmacology forward. However, without reliable and reproducible evidence-based drug formulations designed for use in a range of pediatric patients, safe and consistent clinical practices and outcomes assessments will continue to be difficult to ascertain and the ethics of such research, marginally justifiable. Identification of prime candidate APIs for oral formulation through incorporation and assessment of productionrelated variables will provide a broader integrated clinical, scientific, regulatory, and market basis, allowing for more reliable dosage forms for safe and effective medicines use in children of all ages.

The M4KRC group members derived a list of candidate API molecules by factoring in a number of these pharmacotherapeutic, biopharmaceutical, scientific, manufacturing, and regulatory variables into the selection algorithm that were absent in other rubrics. These additions have assisted in identifying and categorizing prime API candidates suitable for oral formulation development. Finally, the developed algorithm aids in prioritizing useful APIs with finished oral liquid dosage forms available from other countries with direct importation opportunities to North America and beyond. These standardized oral dosage forms await further clinical testing.

\begin{abstract}
Author's contribution
VB-M, RHP, and JJC (the clinical practice group) created the molecule review criteria and algorithm; RBMA and RL (the production group) identified novel formulation methodologies and matched them to the BCS classification system to determine potential targets for mass production. JJC identified molecules available from the British National Formulary that may be suitable for clinical trials. Each group wrote the section of the paper pertaining to their respective sections. Each author reviewed the final version of the paper. VB-M, IC, and RHP finalized the manuscript in its present form. All authors read and approved the final manuscript.
\end{abstract}

\section{Competing interests}

The preparation of this manuscript received no financial subsidy from commercial, governmental, or other non-commercial sources.

The contents of this manuscript have not been presented previously at any scientific conference or published in any conference proceeding, and do not represent the positions of any of the author's respective organizations, commercial enterprises, governments, or employers.

\section{Author details}

${ }^{1}$ Department of Clinical, Social and Administrative Sciences, College of Pharmacy and Department of Pediatrics, Medical School, University of Michigan, Edmonton, AB, Canada. ${ }^{2}$ Med4Kids Research Collaborative, Ltd, Edmonton, AB, Canada. ${ }^{3}$ Clinical Services, Pharmaceutics International, Inc., Hunt Valley, MD, USA. ${ }^{4}$ Pharmaceutical Sciences Division, Faculty of Pharmacy and Pharmaceutical Sciences, University of Alberta, Edmonton, AB, Canada. ${ }^{5}$ Drug Development and Innovation Centre, University of Alberta, Edmonton, AB, Canada. ${ }^{6}$ Drexel University College of Medicine, Philadelphia,
PA, USA. ${ }^{7}$ St. Christopher's Hospital for Children, Philadelphia, PA, USA. ${ }^{8}$ Military and Veterans' Clinical Rehabilitation Research, University of Alberta, Edmonton, $\mathrm{AB}$, Canada.

Received: 16 June 2016 Accepted: 11 October 2016

Published online: 07 November 2016

\section{References}

Abdel-Rahman SM, Amidon GL, Kaul A, Lukacova V, Vinks A, Knipp GT (2012) Summary of the National Institute of Child Health and Human Development-Best pharmaceuticals for children act pediatric formulation initiatives workshop - Pediatric Biopharmaceutics Classification System Working Group. Clin Ther 34:S11-S24

Allen LV, Erickson MA (1996) Stability of labetalol hydrochloride, metoprolol tartrate, verapamil hydrochloride, and spironolactone with hydrochlorothiazide in extemporaneously compounded oral liquids. Am J Health Syst Pharm 53:2304-2309

Almukainzi M, Okumu A, Wei H, Löbenberg R (2014) Simulation of in?vitro dissolution behavior using DDDPlus ${ }^{\text {TT}}$. AAPS PharmSciTech 16:217-221

Amidon GL, Lennernäs H, Shah VP, Crison JR (1995) A theoretical basis for a biopharmaceutic drug classification: The correlation of in?vitro drug product dissolution and in?vivo bioavailability. Pharm Res 12:413-420

Batchelor HK, European Paediatric Formulation Initiative (EUPFI) (2014) Paediatric Biopharma-ceutics Classification System: Current status and future decisions. Int J Pharm 469:251-253

Batchelor HK, Fotaki N, Klein S (2014) Paediatric Biopharmaceutics. Adv Drug Deliv Rev 73:102-126

Better Medicines for Children: From Concept to Reality (2013) European Medicines Agency. Online at: http://ec.europa.eu/health/files/paediatrics/2013_com443/ paediatric_report-com(2013)443_en.pdf. Accessed 9 May 2016.

Charkoftaki G, Valsami G, Macheras P (2012) From supersaturated drug delivery systems to the rising era of pediatric formulations. Chem Biochem Eng $Q$ 2:427-434

Committee on Drugs (2014) Off-label use of drugs in children. Pediatr 133:563-567

Compounding Compendium (2015). Rockville, MD: The United States Pharmacopeial Convention. Online at: http://www.usp.org/sites/default/files/ usp_pdf/EN/products/toc-usp-compounding-compendium.pdf. Accessed 9 May 2016.

Crowley MM, Zhang F, Repka MA, Thumma S, Upadhye SB, Battu SK, McGinity JW, Martin C (2007) Pharmaceutical applications of hot-melt extrusion - part I. Drug Dev Ind Pharm 33:909-926

Dahan A, Wolk O, Kim YH, Ramachandran C, Crippen GM, Takagi T, Bermejo M, Amidon GL (2013) Purely in silico BCS classification: Science based quality standards for the world's drugs. Mol Pharm 10:4378-4390

EMA (2010) Guideline on the investigation of bioequivalence., Appendix III

Flynn JT, Daniels SR, Hayman LL, Maahs DM, McCrindle BW, Mitsnefes M, Zachariah JP, Urbina EM, American Heart Association Atherosclerosis, Hypertension and Obesity in Youth Committee of the Council on Cardiovascular Disease in the Young (2014) Update: ambulatory blood pressure monitoring in children and adolescents: a scientific statement from the American Heart Association. Hypertension 63:1116-1135

Health Canada (2014) Guidance Document., Biopharmaceutics Classification System Based Biowaiver

Jew RK, Soo-Hoo W, Erush SC (2010) Extemporaneous Formulations for Pediatric, Geriatric, and Special Needs Patients. American Society of Health-System Pharmacists, Bethesda, second edition

Laughon MM, Anat D, Tripathi N, Hornik CP, Cohen-Wolkowiez M, Clark RH, Smith PB, Rodriguez W (2014) Drug labeling and exposure in neonates. JAMA Pediatr 168:130-136

Löbenberg R, Amidon GL (2000) Modern bioavailability, bioequivalence and biopharmaceutics classification system. New scientific approaches to international regulatory standards. Euro J Pharm Biopharm 5:3-12

Löbenberg R, Chacra NB, Stippler ES, Shah VP, DeStefano AJ, Hauck WW, Williams RL (2012) Toward global standards for comparator pharmaceutical products: Case studies of amoxicillin, metronidazole, and zidovudine in the Americas. AAPS Journal 14:462-472

Maniruzzaman M, Boateng JS, Snowden MJ (2012) A review of hot-melt extrusion: process technology to pharmaceutical products. ISRN Pharmaceutics:Article ID 436763

Milne C (2011) Economic Issues for Making Available Adequate Drug Dosage Forms. Pediatric Formulations Initiative Workshop. NIHCD, Potomac, Online 
at: http://bpca.nichd.nih.gov/collaborativeefforts/documents/pfi_workshop_ 11-1-2011.pdf. Accessed 9 May 2016

Nahata MC, Allen LV (2008) Extemporaneous formulations. Clin Therapeutics 30:2112-2119

Parrish RH II, Cernak I (2015) Creating a distinct medicines-use system for children: The time is now. Pharmacy 3:72-78

Piasecki J, Waligora M, Dransieka W (2015) Non-beneficial pediatric research: individual and societal interests. Med Health Care Philos 18:103-112

Public Assessment Report for paediatric studies submitted in accordance with Article 45 of Regulation (EC) No1901/2006, as amended. Metoprolol succinate (2013) The Netherlands: Public Assessment Report for paediatric studies submitted in accordance with Article 45 of Regulation (EC) No1901/ 2006, as amended. Metoprolol.

Ramirez E, Laosa O, Guerra P, Duque B, Mosquera B, Borobia AM, Lei SH, Carcas AJ, Frias J (2010) Acceptability and characteristics of 124 human bioequivalence studies with active substances classified according to the Biopharmaceutic Classification System. Br J Clin Pharmacol 70:694-702

Repka MA, Battu SK, Upadhye SB, Thumma S, Crowley MM, Zhang F, Martin C, McGinity JW (2007) Pharmaceutical applications of hot-melt extrusion - part II. Drug Dev Ind Pharm 33:1043-1057

Sweetman SC (ed) (2015), Martindale: The Complete Drug Reference. [online] London: Pharmaceutical Press. http://www.medicinescomplete.com/. Accessed on 9 June 2016

Takagi T, Ramachandran C, Bermejo M, Yamashita S, Yu LX, Amidon GL (2006) A provisional biopharmaceutical classification of the top 200 oral drug products in the United States, Great Britain, Spain, and Japan. Mol Pharm 3:631-643

Tannergren C, Bergendal A, Lennermas H, Abrahamsson B (2009) Toward an increased understanding of the barriers to colonic drug absorption in humans: implications for early controlled release candidate assessment. Mol Pharm 6:60-73

U.S. Department of Health and Human Services Food and Drug Administration Center for Drug Evaluation and Research (CDER) (2000) Guidance for Industry: Waiver of In Vivo Bioavailability and Bioequivalence Studies for Immediate-Release Solid Oral Dosage Forms Based on a Biopharmaceutics Classification System

U.S. Department of Health and Human Services Food and Drug Administration Center for Drug Evaluation and Research (CDER) (2025) Draft Guidance for Industry: Waiver of In Vivo Bioavailability and Bioequivalence Studies for Immediate-Release Solid Oral Dosage Forms Based on a Biopharmaceutics Classification System

Vanchieri C, Stith Butler A, Knutsen A (2008) Addressing the Barriers to Pediatric Drug Development: Workshop Summary Forum on Drug Discovery, Development, and Translation. The National Academies Press, Washington, Online at http://www.nap.edu/catalog/11911.html. Accessed 9 May 2016

Fiftieth Report of the WHO Expert Committee on Specifications for Pharmaceutical Preparations (2016), WHO Technical Report Series 996, Geneva: World Health Organization. Available online: http://apps.who.int/ medicinedocs/documents/s22397en/s22397en.pdf

WHO Expert Committee on Specifications for Pharmaceutical Preparations (2006) WHO Technical Report Series 937, Geneva: World Health Organization. Available online: http://www.who.int/medicines/areas/quality_safety/quality_ assurance/ProposalWaiveVivoBioequivalenceRequirementsModelListEssential MedicinesImmediateReleaseSolidOralDosageFormsTRS937Annex8.pdf

Wu CY, Benet LZ (2005) Predicting drug disposition via application of BCS: Transport/absorption/elimination interplay and development of a biopharmaceutics drug disposition classification system. Pharm Res 22:11-23

\section{Submit your manuscript to a SpringerOpen ${ }^{\circ}$ journal and benefit from:}

- Convenient online submission

Rigorous peer review

- Immediate publication on acceptance

- Open access: articles freely available online

- High visibility within the field

- Retaining the copyright to your article

Submit your next manuscript at $\gg$ springeropen.com 